\title{
INNOVATION CAMP, COLLABORATION BETWEEN UNIVERSITY AND THE CORPORATE WORLD
}

\author{
Paul SVENNEVIG and Rein THORSTENSEN \\ University of Agder, Norway
}

\begin{abstract}
The civil and structural engineering students at University of Agder (UiA) participate annually in an event called "Innovation Camp". This is a collaboration between The Norwegian Public Roads Administration (NPRA), the organisation "Ungt Entreprenørskap" (UE) which is a partner in the worldwide organisation Junior Achievement worldwide (JA worldwide) and UiA.

The National Qualification Framework for Lifelong Learning is the pedagogical base of Innovation Camp. This framework is based on the European Qualifications Framework for Lifelong Learning (EQF).

The roles of the stakeholders are divided as follows; the NPRA provides real life problems for the students to solve. UE is the link between UiA and NPRA and provides the administrative work. UiA supply students and makes sure that each camp has a foundation in the learning outcome of the education.

It is usually 4-5 real life problems for the students to choose from. The students are divided into pre-set groups, who work in teams to solve the selected problem. The students are mentored by experts twice on the first day of the camp. The second day, the students are to present their solution to a semi-final jury, who decides which groups end up in the final. The final jury consists of the CEO of the southern region of NPRA, the dean of the faculty of technology and science, and three representatives for future employers of the students.
\end{abstract}

This article discusses how participation in these camps helps the students improve their innovative skills, which subsequently strengthens the learning outcome from the education.

Keywords: Innovative thinking, problem-solving, collaboration university and the corporate world

\section{INTRODUCTION}

The National Public Road Administration (NPRA) is an authoritative institution for engineering in Norway, and a major employer for engineers. For decades, there has been close cooperation between the regional department of NPRA and University of Agder (UiA), represented by the civil and structural engineering education.

In 2012, NPRA approached UiA to discuss a possible new initiative to support and develop the education; Innovation Camp. The idea of Innovation Camp is that it represents a pedagogical tool for promoting teamwork and innovative thinking, jointly prepared by a three-party collaboration between the corporate world, an academic institution and Ungt Entreprenørskap (UE).

The execution is to present the students to a set of real-life engineering problems, and challenge teams of students to compete for finding the best solution for one of the problems. By introducing several problems, students with different specialisations and pursuing different professional interests can participate in the same competition.

Students are presented to a set of sessions, offering various types of work challenges and learning models; inspirational guest lectures, exercises and reflection on teambuilding, teamwork, feedback, presentations, mentoring, refinement and final competition.

The scope of this paper is to discuss how students gain from participating in Innovation Camp, and how the university pursue continuously quality enhancement of the learning environment through involving in the work leading to this annual event. 


\section{THEORETICAL INSPIRATION}

The framework documentation for the civil and structural engineering education at UiA starts with the introductory vision for the engineer of the future, authored in accordance with the governmental requirements "The national framework for engineering educations":

"As an engineer you will have to use both your analytical and creative skills for solving societal technological problems. You must work in an innovative, structural and targeted way. You must have great skills in the field of creative thinking for analysing, creating possible solutions, evaluating, concluding, carrying out and reporting - in other words be a good entrepreneur. Language skills, both written and oral, in Norwegian and other languages is very important alongside with your science and technology skills. Interacting systems is an important feature in a modern society. Therefore, you must be good at working independently as well as working in teams - with engineers within your field, but also with engineers from other fields, skilled professionals for other professions, and in interdisciplinary teams. As an engineer you will be working with humans, you have an ethical responsibility and an environmental responsibility, and you have great impact on the society."

This vision incorporates requirements in both the Norwegian "National qualification framework for lifelong learning" and the "European qualifications framework for lifelong learning". Both promote skills on innovation, critical thinking, ethics, autonomy, teamwork and decision making under uncertainty.

The values of incorporating working life and real-life experiences in university education, is continuously investigated by didactical researchers. This involvement can be obtained through activities like guest lectures, site visits, industrial given problems for capstone courses etc.

Paine et al. (2003) argue that guest speakers are beneficial for the students; they open the students mind and bring the outside workplace into the classroom [1]. Metrejean (2002) found that the use of guest speakers also contribute to benefit the university; faculty members get in contact with professionals resulting in cooperation, and it confirms the impression that the university is up to date and is in dialogue with the industry [2]. Thorstensen et al. (2018) found that when university is working interconnected with a plurality of actors from the value chain, it promotes real-life tasks and makes the capstone courses socially relevant, all contributing to students' motivation. Also, the university as an institution was found to gain from this kind of interaction, as it secures potential for updating educational programmes to continue educating professionals with relevant competence for working life [3].

In an article focusing on how to include ethics in engineering education, Han (2015) introduces the term "moral motivation", as a strategy to shift away from earlier moral educational paradigms focusing on rule-based ethics and preventive moral education. To achieve this motivation amongst students, Han introduces the necessity of professional exemplar - that is performance by role models [4].

In an article presented at E\&PDE 2018, the idea of offering industrial initiated courses additional to the educational curriculum (Extra Curriculum) is discussed. Strong indications are found that participating students are driven by the desire for extra attractivity in the labour market, gained from demonstrating capacity by doing an extra effort on building competence in addition to doing well in the ordinary curriculum [5].

Research has also found that there are challenges to this kind of industrial involvement of working life into university education. There are severe cultural barriers between industry and university. To promote success in long-time cooperation, it is important to build bilateral awareness on these barriers, and to act to reduce them. To overcome these barriers between industry and university, it is vital for the university to acquire operational competence on industrial language, expectations and modus operandi [3].

\section{METHOD}

Innovation Camp is an innovative learning method based on a three-party collaboration between the corporate world, an academic institution and the organisation Ungt Entreprenørskap (UE). UE is a partner in the worldwide organisation Junior Achievement worldwide (JA worldwide). The educational institutions' commitment to entrepreneurship is both an educational objective and a training strategy. The Innovation Camp programme develops the students' entrepreneurial skills and the educational institutions implement the requirements for innovation and innovation processes laid down in the qualification framework when offering Innovation Camp.

By participating in the Innovation Camp programme, students have the opportunity to learn about and train in varied ways of working and to utilise other learning arenas. Students acquire entrepreneurial skills that include personal qualities and attitudes such as ability and willingness to take initiative, 
innovation and creativity, confidence and willingness to risk. In addition, they gain knowledge of how the business sector works and can apply theory in new ways.

The efforts associated with organising Innovation Camp, is comprehensive. The basis for each new arrangement is evaluation of the past. Each year, success factors and thresholds are evaluated. The quality of the offered problems are analysed enlightened by knowledge on which were selected by the students and which were not. What characteristics made several groups choose some of the challenges, while others were not selected at all? How successful was the mentoring, etc.

All participants - both organisers, mentors and student participants contribute to the evaluation process. The evaluation is done by having the students fill in and return a questionnaire on their opinions of the camp. Furthermore, the originators gather feedback throughout the camp by talking to mentors, students and stakeholders. Lessons learned are filed for quality improvements next year. Only after this evaluation has finished, planning of next year's event can start. The planning work for next year's event starts shortly after evaluation of the past execution. There are usually six meetings between the NPRA, UE and UiA, to make sure that the camp will run smoothly. A central topic is preparing challenges which the students find relevant and interesting. The evaluation on last year's topics are central when preparing the new.

Through this process, the quality of the product offered to the students have continuously improved since the first run in 2012.

\section{RESULTS AND DISCUSSION}

\subsection{Preparing students for participation}

The feedback from the students is always that the university should have prepared them better. At start up, they claim that they do not really understand what they are to participate in. However, the scarcity of information is a conscious choice, because the students are meant to participate without having made up their mind in advance on what they will get out of participation. This way, they get training in starting a fresh project from scratch including having to cooperate in a new team.

\subsection{Inspirational speakers}

Innovation Camp is always kicked off with an inspirational speech. The first year, the inspirational speaker was a local, but internationally famous athlete cyclist, who has done well in the Tour de France and other world class events. His speech was about what inspired him to constantly challenge himself and to aspire for constant improvement in his field of sports. The feedback from the participants, both students and mentors, were negative. The evaluation showed that what we need for inspiring the students is not a well-known name, but a story that they can relate to, when it comes to their studies and plans of the future.

The year after, we chose a different path for this speech. We invited a former student from UiA, who had started touring Norway trying to inspire young people to challenge themselves into doing things that they normally would not do. This speech was based upon his own story of having a learning disability, and how that had been a big challenge for him. He was nearly not accepted as student at UiA. When he started studying and became part of an innovative environment, he started a student project on making an amphibious single engine airplane. He ended up with both completing his BSc and MSc degrees. The feedback from this speech were that it was very interesting, but that he had graduated just a couple of year earlier and that he did not have too many inspirational examples from the world outside the student life.

Since then, the inspirational opening speech has been given by engineers who are experienced and highly respected, well known for quality in execution of the profession. Preferably the person giving the speech to the students should have both successes and failures to talk about, so that the students are told that to be innovative and a founder of new ideas is not a win-or-lose path. It is a path that might take years, with many obstacles, but if the idea is good you can create success from your idea.

This stumbling of ours on the pathway towards the model of using exemplars from the profession - role models - are confirming Han's findings from earlier research [4]. Both organisers and participating students also confirm that these opening lectures contributes to open minds and to bring the outside workplace into the classroom, just as described in theory by [1] and [2]. 


\subsection{Teambuilding activities}

The students are not allowed to choose who they are to work together with during the camp, and they know this prior to start up. Initially, the students do not approve this. However, the feedback after the camp is that this turned out very positive. There are about 80 students participating each year, and most students have established groups or teams in which they frequently cooperate through the education. This means that they are not challenged when it comes to working with new team members and that they know each other so well that it is not always easy to be innovative within this team. The result of pre-set groups given by the organisers, is that they meet students they normally would not work with. Very often these pre-set teams contribute to new team constellations after the camp, when the students return to their ordinary studying activities. The feedback when it comes to the teambuilding tasks is dominantly positive; these activities force new teams to start challenging each other and map strengths and weaknesses within the group form the start. Hence, the students build real life experiences and get to demonstrate this towards future employers. These are vital tools for motivation, according to [3].

\subsection{Real-life challenges and mentoring}

Feedback on the offered challenges the first year was ok, but the students found the span of tasks limited, as most were on road planning. This made us very aware the fact the we must challenge students with a diversity of interests. Following years, we have taken care of interdisciplinarity, including challenges found tantalising by students having diverse interests within civil and structural engineering.

Consequently, the students dominantly evaluate the challenges positively. We also learned quite early that each task must have an "owner" that also is mentoring during the camp. This is very important because this person can answer more intricate questions on the task and how the students should attach the problem. Since we introduced this change, the students are much happier with the mentoring of the challenges. These results are all well within the theoretical findings of [3] and [5] when it comes to the relevance of real-life experiences, and [4] when it comes to the value of exemplars - role models.

The mentoring itself takes place on the first day in camp. Where the students mentored twice throughout the day, this is done with the mentors physically meeting the groups and mentor them on the problem they have chosen. Many of the mentors get so inspired from this work, and the student's enthusiasm, that they make themselves available for the students throughout the night.

\subsection{Overall impressions}

The feedback from the students is very positive when it comes to the overall impression of the arrangement. Very often the students ask if we can have this arrangement every year of their education. The reason for this is that they work with real life problems and that they work very realistically compare to the industry they are to enter in a few years.

This overall feedback is clearly confirming that industrial involvement act as motivational factor for the students, clearly stating that the students recognise the value of cooperation between industry and university, pinpointed by researchers [1-5].

\subsection{A success story}

A few years ago, one of the challenges was to solve how to create an off-ramp from a European Highway, in an area where there really were no room for a traditional structure. One of the student teams came up with a solution that the NPRA had not considered, and which they found interesting. The students documented that the solution did not conflict with the standards and regulations. After finishing the Innovation Camp, NPRA started working to implement in real life the solution originally proposed by the students.

\section{CONCLUSIONS}

1. Innovation Camp has proven to be a good tool for the civil and structural engineering education at UiA, to meet the demands in both the framework for engineering studies and the framework for lifelong learning. It promotes teamwork, critical thinking and innovative thinking. Innovation Camp can also be directed towards promoting ethical and environmental issues.

2. Real life experiences, which are given as the problems should solve, has been well proven to motivate students for progress in their education, in addition to contributing to develop individual competence. 
3. Scarcity on information to the students prior to participation, has successfully been applied as a tool for breaking up established routines and support competitive thinking amongst students.

4. Inspirational speakers are essential for opening session, to promote enthusiasm to open minds and to bring the outside workplace into the classroom. Careful selection of speaker is essential; the speaker should be a role model - experienced in profession and behaviour.

5. Students evaluate team building activities high. These activities in new teams force the members to start challenging each other and to map strengths and weaknesses within the group form the start. Hence, the students build real life experiences and get to demonstrate this towards future employers.

6. The mentors are vital for success. All given problem should have a mentor "owning" it.

\section{REFERENCES}

[1] Payne B.K., Sumter M. and Sun I. Bringing the field into the criminal justice classroom: Field trips, ride-alongs, and guest speakers. 2003. 14(2): p. 327-344.

[2] Metrejean C., Pittman J. and Zarzeski M.T. Guest speakers: reflections on the role of accountants in the classroom. 2002. 11(4): p. 347-364.

[3] Thorstensen R., Larsen I. and Svennevig P. Pursuing diversity in engineering education; a case study on RD\&I-cooperation within civil engineering. 2018. Proceedings of the $20^{\text {th }}$ International Conference on Engineering and Product Design Education Institution of Engineering Designers, The Design Society.

[4] Han H.J.S. and Ethics E. Virtue ethics, positive psychology, and a new model of science and engineering ethics education. Science and Engineering Ethics 2015. 21(2): p. 441-460.

[5] Svennevig P. and Thorstensen R. Extra curriculum, civil and structural engineering studies at University of Agder, Norway. 2018. Proceedings of the $20^{\text {th }}$ International Conference on Engineering and Product Design Education, Institution of Engineering Designers, The Design Society. 